\title{
Using Hicksian Surplus Measures to Examine Consistency of Individual Preferences: Evidence from a Field Experiment
}

\author{
John A. List* \\ Professor \\ University of Maryland and NBER \\ JList@arec.umd.edu
}

\begin{abstract}
This paper pits neoclassical theory against prospect theory by investigating several clean tests of the competing hypotheses. Consistent with previous work, the field experimental data suggest that prospect theory adequately organizes behavior among inexperienced consumers, whereas consumers with intense market experience behave largely in accordance with neoclassical predictions. The data indicate that the convergence in values occurs entirely because of lower Hicksian equivalent surplus values.
\end{abstract}

JEL: C93 (Field Experiments), D11 (Microeconomic Theory)

Key words: endowment effect, field experiment, experience

\footnotetext{
*I would like to thank the Editor and two anonymous reviewers for insightful comments on an earlier version of this study. Don Fullerton, Glenn Harrison, Daniel Kahneman, Liesl Koch, Jack Knetsch, and Matthew Rabin also provided comments that significantly improved this line of research. Seminar participants at Cornell University, Harvard University, University of California-Santa Barbara, University of Chicago, Iowa State University, University of Maryland, North Carolina State, University of Pennsylvania (Wharton), Tilburg University, University of Rhode Island, and University of South Florida also provided useful comments on this line of research. Conference participants at the EAERE meetings in Greece, the NBER meetings in Cambridge, as well as the ESA meetings in Tucson provided useful suggestions. Any errors remain my own. Some of the contents of this study were originally circulated in a paper titled "Neoclassical Theory versus Prospect Theory: Evidence from the Marketplace."
} 


\section{Introduction}

Neoclassical models involve several fundamental postulates. While most of the basic tenets appear to be reasonably met, the basic independence assumption - that preferences are independent of the consumer's current entitlements—-has been directly refuted in several experimental settings (see, e.g., Kahneman, Knetsch, and Thaler, 1990). Although numerous theories have been advanced to explain this anomaly, perhaps the most accepted conjecture invokes psychological effects, and is broadly termed "prospect theory" (Kahneman and Tversky, 1979). Recently, some work examining behavior in naturally occurring markets has suggested that over time consumers learn, and their behavior more closely matches predictions from neoclassical models (List, 2003; 2004a, 2004b). ${ }^{1}$ Yet this work relies primarily on examining trading patterns in markets rather than statements of value, the more important concept for many normative and positive implications. From a positive perspective, a large disparity between Hicksian equivalent surplus and Hicksian compensating surplus essentially renders the invariance result of Coase invalid (Hoffman and Spitzer, 1993). In a normative sense, a value disparity calls into question commonly held interpretations of indifference curves, makes cost/benefit analysis illegitimate, and change the procedure necessary to resolve damage disputes.

The goal of this study is to extend the experimental learning results by examining the shape and structure of Hicksian equivalent surplus and Hicksian compensating

\footnotetext{
${ }^{1}$ Evidence of the learning effect has also been found in laboratory experiments. For example, in a recent study Myagkov and Plott (1997) create an exchange economy in which exposure to loss can be exchanged. If people are loss averse and risk seeking in loss space, "insurance" should sell for less than its fair value and exchanges should occur on the boundaries. Consistent with prospect theory, they find evidence of both phenomena, but the former is attenuated with experience. Considering that useful cognitive capital most likely builds up slowly over months or years rather than in the limited duration of a laboratory experiment (Camerer and Hogarth, 1999), it is understandable that experience in the lab does not attenuate all aspects of loss aversion. This notion highlights the importance of examining behavior in naturally occurring environments.
} 
surplus measures in a well-functioning marketplace. ${ }^{2}$ In this spirit, while the earlier literature examined trading decisions over single items (e.g., sportscards, sports memorabilia, pins, candy bars, and coffee mugs), this study explores curvature of the value function, which necessitates valuation of a number of items. This approach permits a stark test of the competing theories because in such cases the two major theories have contradictory predictions. Prospect theory predicts that Hicksian equivalent surplus will exceed Hicksian compensating surplus and that compensation demanded is concave in the number of relinquished goods due to "diminishing sensitivity." Neoclassical theory predicts equivalence of surplus measures and that compensation demanded is convex in the number of relinquished goods due to quasi-concavity of preferences. In this respect, the experimental design is rare, as it provides a unique test that directly pits the two theories. In addition, the data allow an exploration of the source of the behavior and how experience interacts with valuation decisions. ${ }^{3}$

These predictions are tested using experimental data from actual auctions run in a marketplace. The auction treatments were constructed to provide data that permit a comparison of surplus values as well as a measure of the shape of compensation demanded (equivalent surplus) in the number of relinquished goods. The empirical results provide two major insights. First, whereas Hicksian equivalent surplus is considerably larger than Hicksian compensating surplus for inexperienced agents, the difference converges to zero for experienced agents. Interestingly, the observed convergence is

\footnotetext{
2 I exercise care when claiming that I am observing behavior in a well-functioning marketplace. Borrowing the terminology of Harrison and List (2004), a more accurate description of my experimental design is that of a "framed" field experiment.

${ }^{3}$ To my best knowledge, there has been (i) no previous effort examining the effect of market experience on the shape of compensation demanded and (ii) no evidence gathered on shapes of compensation demanded in framed field experiments.
} 
entirely due to lower Hicksian equivalent surplus values among experienced agents. Second, consistent with this insight, compensation demanded is convex (concave) in the number of items being relinquished for experienced (inexperienced) agents. My preferred interpretation is that the data pattern observed suggests that the learning process at work is one where the psychological effects at the heart of prospect theory are gradually attenuated: experienced agents are more willing to part with their endowments than lesser-experienced agents.

The remainder of this study proceeds as follows. The next section provides a theoretical discussion and the experimental design to test the competing hypotheses. Sections III and IV present the results and conclusions.

\section{Theory and Experimental Design}

Ever since the initial experimental findings that suggested that mere ownership of a good may induce an endowment effect, neoclassical models have been under heavy scrutiny, as their basic independence assumption is clearly violated in such scenarios. Yet a related line of research suggests that this important behavioral pattern is attenuated when agents obtain market experience (Knez, Smith, and Williams, 1985; Coursey, Hovis, and Schulze, 1987; Brookshire and Coursey, 1987; Myagkov and Plott, 1997; List, 2003; 2004a, 2004b). For example, List (2004a) controlled for Hicksian income and substitution effects by examining trading rates of mugs and candy bars at a sportscard show field experiment.

List's (2004a) experimental design is summarized in Figure 1: points A, B, C, and D are the initial endowment levels across the four treatments. Treatment point $A=(0,1)$, 
$\mathrm{B}=(1,1), \mathrm{C}=(0,0)$, and $\mathrm{D}=(1,0)$, where (University of Arizona coffee mug, chocolate candy bar) represent the endowment levels. Insights gained from the treatments come from the choices subjects make when asked if they would like to trade. For example, subjects in Treatment point A (D) are initially endowed with a candy bar (mug) and decide whether to trade for a mug (candy bar). Hence, the subject can either keep her initial endowment or trade it for the other good. In Treatment B subjects are endowed with both goods and must trade both goods for either a mug or a candy bar. Treatment C has subjects simply choosing one of the two goods. ${ }^{4}$ List's (2004a) field observations indicate an inefficiently low number of trades for naïve traders, consistent with prospect theory. But his data show that market experience and the decision to trade in his experiment are positively correlated, thus providing initial evidence that the learning observed in List (2003) transfers across tasks. ${ }^{5}$

List (2004a) was not primarily interested in testing the major theories side-byside, and his results are open to interpretation. For example, the results might be suggesting that certain classes of consumers derive utility merely from trading (perhaps this is the reason they participate in the sportscard market in the first place). With an eye toward testing the competing hypotheses side-by-side, and more fully exploring learning effects over statements of value, I turn to the experimental design, which permits an analysis of explicit statements of willingness to accept (WTA) and willingness to pay

\footnotetext{
${ }^{4}$ Unless one wishes to invoke more stringent assumptions on the convexity of the value function in the loss domain across goods, comparing individual decisions across points $\mathrm{B}$ and $\mathrm{C}$ are not enlightening.

5 While the data in this study do not discern between treatment effects (market experience or learning effects) versus selection effects (subject pool), List (2003) presents evidence that suggests that learning (market experience) is important. This inference follows from a panel data regression that he ran: he observed trading decisions of sports memorabilia for the same agents at two points in time, controlled for selection effects in the regression, and found that market experience and the decision to trade were correlated. Thus, I follow this learning (market experience) conjecture in the discussion, and exchange learning and market experience as the reasons for the change in behavior.
} 
(WTP) in an incentive-compatible elicitation mechanism: a Vickrey sealed bid $2^{\text {nd }}$ price auction. ${ }^{6}$

Figure 2, which assumes quasi-concave utility functions, illustrates the experimental design (which is closely related to Horowitz, McConnell, and Quiggin (1999)). In Figure 2, G represents extra large fine Swiss chocolate bars and $\$$ denotes dollars (note that while numerical subscripts on $\mathrm{g}$ represent number of candy bars, subscripts on $\$$ are for notational convenience only and do not depict actual dollar figures). To obtain statements of value, I randomly endowed subjects at $\left(\mathrm{g}_{0}, \$_{3}\right)$ or $\left(\mathrm{g}_{3}, \$_{0}\right)$. Subjects endowed at $\left(\mathrm{g}_{0}, \$_{3}\right)$ stated three Hicksian compensating surplus (WTP) values: their maximum WTP for $\mathrm{g}_{1}-\mathrm{g}_{0}, \mathrm{~g}_{2}-\mathrm{g}_{0}$, and $\mathrm{g}_{3}-\mathrm{g}_{0}$ units of $\mathrm{G}$ (denoted $\mathrm{WTP}_{1}, \mathrm{WTP}_{2}$, and $\left.\mathrm{WTP}_{3}\right)$. Likewise, subjects endowed at $\left(\mathrm{g}_{3}, \$_{0}\right)$ stated three Hicksian equivalent surplus (WTA) values: their minimum WTA to sell one, two, or three of their candy bars (i.e., to relinquish $\mathrm{g}_{3}-\mathrm{g}_{2}, \mathrm{~g}_{3}-\mathrm{g}_{1}$, and $\mathrm{g}_{3}-\mathrm{g}_{0}$ of their candy bars, denoted $\mathrm{WTA}_{1}, \mathrm{WTA}_{2}$, and $\mathrm{WTA}_{3}$ ). Each of the subjects knew that only one of the three auctions, to be determined randomly, would be carried out for real.

Note that a simple exercise of randomly allocating subjects at $\left(\mathrm{g}_{3}, \$_{0}\right)$ and $\left(\mathrm{g}_{0}, \$_{0}\right)$ and eliciting minimum WTA and maximum WTP values does not yield tremendous insights since both prospect theory and neoclassical theory predict a value disparity. Neoclassical theory predicts divergence due to income (shifts in the indifference curve) and substitution (curvature of the indifference curves) effects. This can be seen in Figure 2 via $\mathrm{WTA}_{3}=\$_{3}-\$_{0}>\mathrm{WTP}_{3}=\$_{0}-\$_{4}$. Prospect theory invokes psychological effects to predict divergences. Thus, it is important to control for Hicksian income and substitution effects by compensating WTP subjects to ensure that subjects are moving along the same

${ }^{6}$ This institution has proven straightforward in other field experiments (List, 2001). 
indifference curve. The amount of compensation used in the WTP treatment is the average $\mathrm{WTA}_{3}$ (i.e., the average dollar value from the $\mathrm{WTA}_{3}$ auction). And, to ensure the proper compensation, I completed the WTA treatment prior to beginning the WTP treatment. ${ }^{7}$

The treatments were run on the floor of a sportscard show in Tucson, Arizona. Each participant's experience followed four steps: (1) completing a survey, (2) learning the auction rules, (3) considering the bid (offer), and (4) concluding the transaction and exit interview. In Step 1, the monitor approached individuals entering the trading card show and inquired about their interest in filling out a survey. ${ }^{8}$ If the individual agreed, then the monitor explained that in return for completing the survey the subject would receive an endowment (either three candy bars or the average $\mathrm{WTA}_{3}$ - see above). After the monitor physically gave the subject the appropriate endowment, the subject proceeded to fill out the survey. The monitor worked one-on-one with the participant and no time limit was imposed. In Step 2, the monitor informed the subject that she now had the opportunity to bid (offer) in an auction for the goods on the table (their goods). After inspecting the goods, the subject learned the rules of the Vickrey $2^{\text {nd }}$ price auction as well as the randomization mechanism (Appendix B contains the WTP experimental instructions).

In the WTP (WTA) treatment, after completing the survey, learning the auction rules, and examining the goods, each participant privately wrote three bids (offers) on the bidding sheet and placed it in an opaque box. The monitor informed the participant that

\footnotetext{
7 Thus, when I refer to "randomization" into treatment, the reader should be aware that subjects in the WTA auctions arrived at the show later in the day than the subjects in the WTP auctions arrived.

8 The survey is contained in Appendix A.
} 
her bidding sheet would not be opened until after the show and that all bids/offers would be destroyed when the research project was completed. Each subject worked one-on-one with the monitor and no time limit was imposed on her inspection of the goods. In Step 4, the monitor explained that if the participant won the auction, she would be contacted by email or telephone within three days. Upon receipt of payment, the monitor would send her the candy bars (or money), postage paid.

Before proceeding, I should mention a few important aspects of the experimental design. First, subjects were randomly placed into either the WTA or WTP treatment, and competed against others in the same treatment. Second, no subject participated in more than one treatment. Third, since I am not testing the incentive-compatibility of the mechanism, and want to avoid any excess noise, I informed subjects that it was in their best interest to bid (offer) their true value in the auctions. I reinforced this notion via several examples that illustrated the optimal strategy of truth-telling.

\section{Theoretical Predictions}

Across these auction treatments neoclassical theory and prospect theory have quite disparate predictions. A first difference in predictions is that neoclassical theory conjectures $\mathrm{WTA}_{3}=\mathrm{WTP}_{3}$, whereas prospect theory predicts $\mathrm{WTA}_{3}>\mathrm{WTP}_{3}$. This first test, therefore, represents an examination of whether individuals' indifference curves are reversible (i.e., individuals have consistent preferences). Any other comparisons of WTA and WTP are not enlightening since both theories predict a disparity-offers and bids represent movements along different segments of the same indifference curve. ${ }^{9}$

\footnotetext{
9 This is true unless there is infinite substitutability between money and candy bars, in which case neoclassical theory predicts no value disparity, whereas prospect theory predicts divergences.
} 
While further comparison of WTA and WTP values may not yield considerable insights, indifference curve convexity implies convexity of the expenditure function in g. ${ }^{10}$ Because the expenditure function is strictly convex in g, compensation demanded will also be strictly convex in $\mathrm{g}$. In this case, neoclassical theory yields several predictions about the nature of compensation demanded in the number of goods relinquished: $2 \mathrm{WTA}_{1}<\mathrm{WTA}_{2}, 3 \mathrm{WTA}_{1}<\mathrm{WTA}_{3}, 3 \mathrm{WTA}_{2}<2 \mathrm{WTA}_{3}$, and $\mathrm{WTA}_{1}+\mathrm{WTA}_{3}<2 \mathrm{WTA}_{2}$.

Alternatively, prospect theory conjectures that a value function exists that is (i) measured over deviations from a reference point, (ii) convex for losses and concave for gains, and (iii) initially steeper for losses than for gains (Tversky and Kahneman, 1991). Hence, a major conjecture of prospect theory is diminishing sensitivity, or that small gains are disproportionately more attractive relative to large gains, and small losses disproportionately aversive relative to large losses. Intuitively, convexity of the value function in losses is motivated by the idea that the decline in value from a loss of $\$ 1100$ to a loss of $\$ 1200$ is less than the decline in value from a loss of $\$ 100$ to a loss of $\$ 200$. In this sense, prospect theory predicts concavity of the compensation demanded function if the convexity of the value function for the auctioned good in the loss domain is sufficiently large relative to the concavity of the value function for money in the gain domain. In this case, which seems plausible given empirical results in the literature, prospect theory again has predictions that are directly at odds with neoclassical theory: $2 \mathrm{WTA}_{1}>\mathrm{WTA}_{2}, 3 \mathrm{WTA}_{1}>\mathrm{WTA}_{3}, 3 \mathrm{WTA}_{2}>2 \mathrm{WTA}_{3}$, and $\mathrm{WTA}_{1}+\mathrm{WTA}_{3}>2 \mathrm{WTA}_{2}$. Of

\footnotetext{
${ }^{10}$ As shown in Horowitz et al. (1999), this can be proven as follows: if the utility function $\mathrm{u}(\mathrm{g}, \$)$ is quasiconcave in $(\mathrm{g}, \$)$, then the set $\mathrm{S}\left(\mathrm{q}, \mathrm{u}^{*}\right)=\left\{\$ \mid \mathrm{u}(\mathrm{g}, \$) \geq \mathrm{u}^{*}\right\}$ is convex. Because $\mathrm{S}(\mathrm{g})$ is convex, the set $\lambda \mathrm{S}\left(\mathrm{g}_{0}\right)+$ $(1-\lambda) \mathrm{S}\left(\mathrm{g}_{1}\right) \subset \mathrm{S}\left(\lambda \mathrm{g}_{0}+(1-\lambda) \mathrm{g}_{1}\right)$ for $0<\lambda<1$. Hence, we have $\mathrm{m}\left(\mathrm{p}, \mathrm{g}_{0}, \mathrm{u}^{*}\right)=\inf \left\{\$ \cdot \mathrm{p} \mid \$ \in \mathrm{S}\left(\mathrm{g}_{0}\right)\right\} ; \mathrm{m}\left(\mathrm{p}, \mathrm{g}_{1}, \mathrm{u}^{*}\right)=$ $\inf \left\{\$ \cdot p \mid \$ \in \mathrm{S}\left(\mathrm{g}_{1}\right)\right\} ;$ and $\mathrm{m}\left(\mathrm{p}, \lambda \mathrm{g}_{0}+(1-\lambda) \mathrm{g}_{1}, \mathrm{u}^{*}\right)=\inf \left\{\$ \cdot \mathrm{p} \mid \$ \in \mathrm{S}\left(\lambda \mathrm{g}_{0}+(1-\lambda) \mathrm{g}_{1}\right)\right\}$. Convexity in $\mathrm{g}$ requires $\lambda \mathrm{m}\left(\mathrm{p}, \mathrm{g}_{0}, \mathrm{u}^{*}\right)+(1-\lambda) \mathrm{m}\left(\mathrm{p}, \mathrm{g}_{1}, \mathrm{u}^{*}\right) \geq \mathrm{m}\left(\mathrm{p}, \lambda \mathrm{g}_{0}+(1-\lambda) \mathrm{g}_{1}, \mathrm{u}^{*}\right)$. The first expression can be rewritten $\lambda \mathrm{m}\left(\mathrm{p}, \mathrm{g}_{0}, \mathrm{u}^{*}\right)+(1-\lambda) \mathrm{m}\left(\mathrm{p}, \mathrm{g}_{1}, \mathrm{u}^{*}\right)=\inf \left\{\$ \cdot \mathrm{p} \mid \$ \in \lambda \mathrm{S}\left(\mathrm{g}_{0}\right)+(1-\lambda) \mathrm{S}\left(\mathrm{g}_{1}\right)\right\}$. But, inf $\left\{\$ p \mid \$ \in \lambda \mathrm{S}\left(\mathrm{g}_{0}\right)+(1-\lambda) \mathrm{S}\left(\mathrm{g}_{1}\right)\right\} \geq$
} 
course, examination of the shape of WTP yields no discernible tests since both theories predict that WTP is concave in $\mathrm{g} .{ }^{11}$

\section{Results}

Table 1 provides a statistical description of the subject characteristics in both treatments. Standard deviations of the variables reveal that there is a considerable amount of subject variability in the level of trading intensity and years of market experience, permitting an analysis of the effect of market experience on behavior. In the data analysis below, I focus on the effects of trading intensity on behavior. Yet I should note that if I use a measure of the stock of market experience - the product of trading intensity and years of market experience-empirical results are qualitatively similar. ${ }^{12}$

Table 2 provides sample statistics for WTA and WTP measures of value across several experience thresholds. In choosing thresholds for these samples, I considered both the mean number of trades in a typical month $(\approx 5)$ and its standard deviation $(\approx 5)$. A first important insight gained from Table 2 is the discrepancy between Hicksian equivalent surplus and Hicksian compensating surplus for the three candy bars in the pooled data (row 1). While compensation demanded is $\$ 14.78$, WTP is only $\$ 7.73$.

$\inf \left\{\$ \cdot p \mid \$ \in S\left(\lambda g_{0}+(1-\lambda) g_{1}\right)\right\}$ because $\lambda S\left(g_{0}\right)+(1-\lambda) S\left(g_{1}\right) \subset S\left(\lambda g_{0}+(1-\lambda) g_{1}\right)$. Therefore, the expenditure function is convex in $\mathrm{g}$ (see Maler, 1974).

${ }^{11}$ I should note that I am not the first to examine shapes of compensation demanded - see Brookshire and Coursey (1987) for an early example of a study that gathered statements of compensation demanded. For a more recent treatment see Horowitz et al. (1999), who conduct similar exercises to those herein.

12 The astute reader will note that the survey asked "Approximately how many trades (cards or memorabilia) do you make in a typical month? ___. Note that trades could include pokemon cards, sportscards, other trading cards, and sports memorabilia." While "trades" might appear to be a vague term (i.e., perhaps it includes money-for-goods transactions), in this marketplace the terminology "trade" is ubiquitously recognized to be a good(s)-for-good(s) transaction. 
This value difference is significant at the $\mathrm{p}<.01$ level using a large-sample $\mathrm{t}$-test $(\mathrm{t}=$ 6.30) and suggests that preferences are inconsistent. ${ }^{13}$

Parsing the data into subcategories yields interesting insights: predictions from prospect theory are met in the inexperienced consumer group, as $\mathrm{WTA}_{3}(\$ 18.36)$ is significantly greater than $\mathrm{WTP}_{3}(\$ 7.54)$ at the $\mathrm{p}<.01$ level $(\mathrm{t}=7.30) .{ }^{14}$ Yet data collected from the more experienced groups align with neoclassical predictions: neither experienced consumers' values $\left(\mathrm{WTA}_{3}=\$ 10.10, \mathrm{WTP}_{3}=\$ 7.89\right)$ nor intense consumers' values $\left(\mathrm{WTA}_{3}=\$ 8.21, \mathrm{WTP}_{3}=\$ 7.43\right)$ are significantly different at the $\mathrm{p}<.05$ level (experienced: $\mathrm{t}=1.72$; intense: $\mathrm{t}=0.72$ ). Interestingly, the convergence of values is entirely due to lower Hicksian equivalent surplus values among experienced agentsinexperienced consumers provide a $\mathrm{WTA}_{3}$ value of $\$ 18.36$, whereas intense consumers provide a $\mathrm{WTA}_{3}$ value $(\$ 8.21)$ that is $\$ 10.15$ lower, a difference of 55 percent, which is significant at the $\mathrm{p}<.01$ level $(\mathrm{t}=6.70)$. A comparison of $\mathrm{WTP}_{3}$ values across these same subject groups provides negligible value differences (\$7.54 versus \$7.43). Interestingly, WTP is concave in $\mathrm{g}$ for all subsamples, as predicted by both theories.

A further test of the two theories requires a more careful exploration of the curvature of Hicksian equivalent surplus measures over the number of relinquished goods. Table 3 presents summary statistics across the curvature measures for each of the subsamples. Panel A in Table 3 provides means and standard deviations for the measures:

\footnotetext{
13 These results, and those discussed below, are consistent across parametric and non-parametric tests.

${ }^{14}$ Recall that all subjects randomly allocated into the WTP treatment received the average offer from the $\mathrm{WTA}_{3}$ treatment. Considering the mean WTA values across subject types, some subjects were likely overendowed (experienced consumers) while others were likely under-endowed (inexperienced consumers). This design decision, therefore, may have compromising effects if subjects' WTP is highly responsive to this change in wealth. To address this potential shortcoming, I returned to the same marketplace and ran three ancillary WTP treatments where I first determined bidders' experience levels, and then endowed agents according to the WTA values in Table 2 (\$18.36, $\$ 10.10$, and \$8.21). Using data from more than 50 agents, results are qualitatively identical to those in Table 2.
} 
$\mathrm{WTA}_{2}-2 \mathrm{WTA} 1, \mathrm{WTA}_{3}-3 \mathrm{WTA}_{1}, 2 \mathrm{WTA}_{3}-3 \mathrm{WTA}_{2}$, and $2 \mathrm{WTA}_{2}-\mathrm{WTA}_{1}-\mathrm{WTA}_{3}$. A negative entry in panel A indicates a tendency toward concavity of compensation demanded, whereas a positive figure indicates a tendency toward convexity. The data pattern strongly supports results from Table 2. For inexperienced consumers, three out of the four measures support prospect theory: at the $\mathrm{p}<.05$ level the data in columns 1-3 all support concavity of the Hicksian equivalent surplus measures. The fourth measure in column 4 is directionally correct but not significant at conventional levels.

Data gathered from the experienced and intense consumers provide evidence that supports neoclassical theory-convexity of compensation demanded is evident. For experienced consumers, the differences are significant at the $\mathrm{p}<.05$ level for the first two column measures and at the $\mathrm{p}<.08$ and $\mathrm{p}<.15$ levels for the last two column measures. For intense consumers the results are sharper, as significance is achieved at the $\mathrm{p}<.05$ level for the first three measures and at the $\mathrm{p}<.12$ level for the fourth measure.

Panel B in Table 3 presents a much more disaggregated look at the WTA data by compiling the number of subjects that comply with neoclassical theory (denoted NT) and prospect theory (denoted PT) for each of the four curvature measures. ${ }^{15}$ Besides providing a robustness check of whether a few outliers are driving the results displayed in panel A, these figures provide a sense of individual-level behavior. One can draw inferences from these figures by moving up and down rows in any given column, or across columns in any given row.

\footnotetext{
15 A computed value of zero indicates linearity and is not counted as following either theory; thus, the summation of the number of subjects following either theory (for any measure) is not equal to the number of subjects that participated.
} 
Overall, data in panel B provide several insights comparable to inference gained from panel A. First, in the pooled data the number of subjects conforming to neoclassical theory and prospect theory is roughly equivalent across all four curvature measures. Second, across the four curvature measures, 41-65 percent (18-29 percent) of inexperienced agents conform to prospect theory (neoclassical theory). A test of proportions indicates that for curvature measures in columns 1-3, a significantly greater proportion of inexperienced agents conform to prospect theory than to neoclassical theory $(\mathrm{z}=2.76 ; \mathrm{z}=3.94 ; \mathrm{z}=2.46)$.

Third, behavior of 50-70 percent (19-23 percent) of experienced agents is in line with predictions of neoclassical theory (prospect theory). Using a test of proportions, I find that for all four curvature measures these differences are significant at the $p<.05$ level. Fourth, 50-72 percent (16-22 percent) of intense consumers conform to neoclassical predictions (prospect theory predictions). Again, a proportions test indicates that in all four curvature cases these differences are significant at the $p<.05$ level. Finally, comparing the proportion of subjects who conform to neoclassical theory or prospect theory across the inexperienced and experienced consumer samples, I find that for each of the four curvature measures, experienced (inexperienced) consumers are significantly more likely to behave in accordance with neoclassical theory (prospect theory) than inexperienced (experienced) consumers.

Although analysis of the raw data provides evidence suggesting that market experience and offer curvature are correlated, there has been no attempt to control other factors that may affect the bid/offer level. To provide conditional insights into the auction data, I estimate the following bid/offer model: 


$$
Y=\mathrm{f}\left(\alpha+\beta^{\prime} X\right)
$$

where $Y$ is subject i's bid or offer; and $X$ includes subject-specific variables that may affect the bid or offer: trading intensity, years of market experience, gender, income, education, and age. For the WTP equation, I use a Tobit specification since there are zero bids in the data.

Summary estimates are presented in Table 4. The empirical results strongly support the unconditional findings. For example, the coefficient estimate of trading intensity in the WTA specification is significantly different from zero at the $\mathrm{p}<.01$ level and implies that a one standard deviation increase in intensity $(\approx 5.2)$ is correlated with a $\$ 3.70$ decrease in WTA. Results from the WTP specification suggest that market intensity is not an important marginal influence on WTP values. Again, I should note that if I examine a measure of the stock of market experience, empirical results are qualitatively similar.

Combining insights gained across the statistical analyses provides the following insight: while prospect theory can go a long way in explaining behavior of "naïve" subjects, behavior converges to the neoclassical prediction as subjects gain market experience. To see this, consider Figure 3, which provides a summary of individual behavior across the WTA and WTP treatments. The figure includes data across the 120 subjects and makes the WTA/WTP ratio a function of trading intensity. Figure 3 clearly shows that individual behavior converges to the neoclassical prediction as trading experience intensifies. In light of the extant body of psychological evidence that reports limited transfer of learning across tasks, these results are quite surprising given that these 
consumers have seemingly overcome the endowment effect in situations beyond specific problems they have previously encountered. ${ }^{16}$

The richness of the data also permits an examination of the underlying learning process. In this sense, the results in this study rule out many potential explanations that could not be entirely discarded in previous data sets (List, 2003; 2004a). For example, preference uncertainty and subjects obtaining utility from the trading exercise cannot credibly explain the auction results herein. Yet the data are broadly consistent with at least one potential explanation: via market interaction and numerous arbitrage opportunities, practiced agents have learned to overcome the "pain" of selling and treat the good leaving their endowment as an opportunity cost rather than a loss (see also Loewenstein and Kahneman, 1991). While psychological effects have been extremely popular in explaining the endowment effect anomaly, the data herein suggest that psychological effects may also help to explain the attenuation of the anomaly.

\section{Concluding Remarks}

Indifference curves are traditionally drawn without reference to current entitlements. In practice, this convention implies that with small income effects and many available substitutes, differences between equivalent and compensating variation are negligible. From a positive perspective, this assumption represents a necessary condition for the invariance result of Coase. In a normative sense, this interpretation of indifference curves legitimizes cost/benefit analysis and provides a basis to resolve damage disputes. Yet

\footnotetext{
16 One potential explanation of this result revolves around the experience gained by participants in this market. Their experience is that items - of all sorts in this marketplace-in their possession are not necessarily consumed. In this sense, candy bars and mugs might not be too dissimilar from sportscards and sports memorabilia.
} 
substantial evidence has mounted that illustrates the importance of entitlements: in an influential experimental study, Kahneman, Knetsch, and Thaler (1990) provide compelling evidence to reject the basic independence assumption. These experimental findings have been robust across unfamiliar goods, such as irradiated sandwiches, and common goods, such as chocolate bars, persuading some of the most ardent supporters of neoclassical theory to doubt the validity of certain neoclassical postulates.

In this study, I make use of data from a framed field experiment to perform several clean tests that pit neoclassical theory against prospect theory. Several insights are obtained. First, prospect theory is found to have strong predictive power for inexperienced consumers. Second, for those consumers who have had a considerable amount of exchange opportunity in the sportscard marketplace, neoclassical theory predicts reasonably well: I find sharp evidence that behavior approaches the neoclassical prediction for experienced agents. In light of the extant body of psychological evidence that reports limited transfer of learning across tasks (Loewenstein, 1999), these results are surprising. The tentative conclusion regarding the underlying learning process at work is that agents with intense market experience have learned to part with their entitlements, suggesting that attenuation of the anomaly appears to take place on the sell side of the market rather than on the buy side. ${ }^{17}$ More research in this area is certainly necessary to explore the generality of the results herein.

17 Of course, this result is observationally equivalent to these agents "becoming prone not to immediately code goods in their possession as items for consumption" and represents a good line of future research. I thank an anonymous reviewer for this point. 


\section{References}

Brookshire, D. and Coursey, D. (1987), Measuring the Value of a Public Good: An Empirical Comparison of Elicitation Procedures, American Economic Review 77, 554-566.

Camerer, C.F. and Hogarth, R. (1999), The Effects of Financial Incentives in Experiments: A Review and Capital-Labor-Production Framework, Journal of Risk and Uncertainty 19, 7-42.

Coursey, D., Hovis, J., and Schulze, W. (1987), The Disparity Between Willingness to Accept and Willingness to Pay Measures of Value, Quarterly Journal of Economics 102, 679-690.

Harrison, G.W. and List, J.A. (2004), Field Experiments, Journal of Economic Literature XLII, 1009-1055.

Hoffman, E. and Spitzer, M. (1993), Willingness to Pay vs. Willingness to Accept: Legal and Economic Implications, Washington University Law Quarterly 71, 59-114.

Horowitz. J.K., McConnell, K.E. and Quiggin, J. (1999), Test of Competing Explanations of Compensation Demanded, Economic Inquiry 37, 637-646.

Kahneman, D., Knetsch, J.L. and Thaler, R.H. (1990), Experimental Tests of the Endowment Effect and the Coase Theorem, Journal of Political Economy 98, $1325-1348$.

Kahneman, D. and Tversky, A. (1979), Prospect Theory: An Analysis of Decision Under Risk, Econometrica 47, 263-291.

Knez, P., Smith, V.L. and Williams, A. (1985), Individual Rationality, Market Rationality, and Value Estimation, American Economic Review 75, 397-402. 
List, J.A. (2001), Do Explicit Warnings Eliminate the Hypothetical Bias in Elicitation Procedures? Evidence from Field Auctions for Sportscards, American Economic Review 91, 1498-1507.

List, J.A. (2003), Does Market Experience Eliminate Market Anomalies?, Quarterly Journal of Economics 118, 41-71.

List, J.A. (2004a), Neoclassical Theory Versus Prospect Theory: Evidence from the Marketplace, Econometrica 72, 615-625.

List, J.A. (2004b), Substitutability, Experience, and the Value Disparity: Evidence from the Marketplace, Journal of Environmental Economics and Management 47, 486509.

Loewenstein, G. (1999), Experimental Economics from the Vantage-Point of Behavioural Economics, Economic Journal 109, F25-F34.

Loewenstein, G. and Kahneman, D. (1991), Explaining the Endowment Effect, Carnegie Mellon Working Paper.

Maler, K.-G. (1974), Environmental Economics: A Theoretical Inquiry, Johns Hopkins University Press, Baltimore, MD.

Myagkov, M. and Plott, C. (1997), Exchange Economies and Loss Exposure: Experiments Exploring Prospect Theory and Competitive Equilibria in Market Environments, American Economic Review 87, 801-828.

Tversky, A. and Kahneman, D. (1991), Loss Aversion in Riskless Choice: A ReferenceDependent Model, Quarterly Journal of Economics 106, 1039-1061. 
Table 1. Selected Characteristics of Participants

\begin{tabular}{|c|c|c|}
\hline & $\begin{array}{c}\text { Mean } \\
\text { (Std. dev.) } \\
\text { WTA }\end{array}$ & $\begin{array}{c}\text { Mean } \\
\text { (Std. dev.) } \\
\text { WTP }\end{array}$ \\
\hline Trading intensity & $\begin{array}{c}5.07 \\
(5.24)\end{array}$ & $\begin{array}{c}5.23 \\
(4.82)\end{array}$ \\
\hline $\begin{array}{l}\text { Yrs. of market } \\
\text { experience }\end{array}$ & $\begin{array}{c}10.13 \\
(10.71)\end{array}$ & $\begin{array}{c}8.92 \\
(9.90)\end{array}$ \\
\hline Income & $\begin{array}{l}3.55 \\
(2.27)\end{array}$ & $\begin{array}{c}3.78 \\
(2.24)\end{array}$ \\
\hline Age & $\begin{array}{c}31.74 \\
(13.42)\end{array}$ & $\begin{array}{c}31.61 \\
(14.38)\end{array}$ \\
\hline Gender (\% male) & $\begin{array}{c}0.83 \\
(0.38)\end{array}$ & $\begin{array}{c}0.83 \\
(0.38)\end{array}$ \\
\hline Education & $\begin{array}{c}3.51 \\
(1.70)\end{array}$ & $\begin{array}{c}3.48 \\
(1.68)\end{array}$ \\
\hline$N$ & 60 & 60 \\
\hline \multicolumn{3}{|c|}{$\begin{array}{l}\text { Notes: } \\
\text { 1. Trading intensity represents the number of trades made in a typical month. } \\
\text { 2. } \text { Yrs. of market experience denotes years that the subject has been active in the market. } \\
\text { 3. Income denotes categorical variable (1-8): 1) Less than } \$ 10,000, \text { 2) } \$ 10,000 \text { to } \$ 19,999,3) \$ 20,000 \text { to } \\
\$ 29,999,4) \$ 30,000 \text { to } \$ 39,999,5) \$ 40,000 \text { to } \$ 49,999,6) \$ 50,000 \text { to } \$ 74,999,7) \$ 75,000 \text { to } \$ 99,999 \text { 8) } \\
\$ 100,000 \text { or over. } \\
\text { 4. Age denotes actual age in years. } \\
\text { 5. Gender denotes categorical variable: 0 if female, } 1 \text { if male. } \\
\text { 6. Education denotes categorical variable 1) Eighth grade or less, 2) High School 3) 2-Year College, 4) } \\
\text { Other Post-High School, 5) 4-Year College, 6) Graduate School Education. }\end{array}$} \\
\hline
\end{tabular}


Table 2. WTA/WTP Sample Statistics Across Consumer Types

\begin{tabular}{|c|c|c|c|c|c|c|}
\hline Group & $\begin{array}{c}\text { WTA } 1 \\
\text { Mean } \\
\text { (Std. dev.) } \\
\end{array}$ & $\begin{array}{c}\text { WTA2 } \\
\text { Mean } \\
\text { (Std. dev.) } \\
\end{array}$ & $\begin{array}{c}\text { WTA }_{3} \\
\text { Mean } \\
\text { (Std. dev.) } \\
\end{array}$ & $\begin{array}{c}\mathbf{W T P}_{1} \\
\text { Mean } \\
\text { (Std. dev.) } \\
\end{array}$ & $\begin{array}{c}\mathbf{W T P}_{2} \\
\text { Mean } \\
\text { (Std. dev.) } \\
\end{array}$ & $\begin{array}{c}\mathbf{W T P}_{\mathbf{3}} \\
\text { Mean } \\
\text { (Std. dev.) } \\
\end{array}$ \\
\hline $\begin{array}{l}\text { Pooled } \\
\quad \text { Bid or Offer } \\
\quad(\mathrm{WTA}, \mathrm{n}=60) \\
(\mathrm{WTP}, \mathrm{n}=60)\end{array}$ & $\begin{array}{l}5.58 \\
(3.7)\end{array}$ & $\begin{array}{c}10.04 \\
(5.4)\end{array}$ & $\begin{array}{c}14.78 \\
(7.0)\end{array}$ & $\begin{array}{l}4.11 \\
(2.5)\end{array}$ & $\begin{array}{l}5.99 \\
(3.6)\end{array}$ & $\begin{array}{c}7.73 \\
(5.0)\end{array}$ \\
\hline $\begin{array}{l}\text { Inexperienced ce } \\
\text { Bid or Offer } \\
\text { (WTA, n=34) } \\
\text { (WTP, } n=27)\end{array}$ & $\begin{array}{c}\text { nsumers } \\
7.75 \\
(3.5)\end{array}$ & $\begin{array}{c}13.16 \\
(4.6)\end{array}$ & $\begin{array}{c}18.36 \\
(6.1)\end{array}$ & $\begin{array}{l}4.08 \\
(3.0)\end{array}$ & $\begin{array}{l}5.91 \\
(3.7)\end{array}$ & $\begin{array}{c}7.54 \\
(5.2)\end{array}$ \\
\hline $\begin{array}{l}\text { Experienced con } \\
\text { Bid or Offer } \\
\text { (WTA, n=26) } \\
\text { (WTP, } \mathrm{n}=33)\end{array}$ & $\begin{array}{c}\text { umers } \\
2.74 \\
(1.31)\end{array}$ & $\begin{array}{l}5.96 \\
(3.0)\end{array}$ & $\begin{array}{c}10.10 \\
(5.0)\end{array}$ & $\begin{array}{l}4.14 \\
(2.0)\end{array}$ & $\begin{array}{l}6.05 \\
(3.5)\end{array}$ & $\begin{array}{l}7.89 \\
(4.8)\end{array}$ \\
\hline $\begin{array}{l}\text { Intense consume } \\
\text { Bid or Offer } \\
\text { (WTA, } \mathrm{n}=18 \text { ) } \\
\text { (WTP, } \mathrm{n}=15)\end{array}$ & $\begin{array}{c}2.29 \\
(0.83)\end{array}$ & $\begin{array}{l}5.00 \\
(1.9)\end{array}$ & $\begin{array}{l}8.21 \\
(2.5)\end{array}$ & $\begin{array}{l}3.87 \\
(1.8)\end{array}$ & $\begin{array}{l}6.28 \\
(3.3)\end{array}$ & $\begin{array}{c}7.43 \\
(3.7)\end{array}$ \\
\hline
\end{tabular}

Note: "Inexperienced" consumers are those subjects that trade fewer than 5 times in a typical month; "Experienced" consumers are those subjects that trade 5 or more times in a typical month; "Intense" consumers are those subjects that trade 10 or more times per month. In choosing these thresholds, I considered both the mean number of trades in a typical month $(\approx 5)$ and its standard deviation $(\approx 5)$ (see Table 1). Thus, "Inexperienced" consumers are those subjects who are below the average trading rate; "Experienced" consumers are those subjects who are above the average trading rate; and "Intense" consumers are those consumers at least one standard deviation above the average trading rate. 


\section{WTA $_{2}-2 W T A_{1}$ WTA $_{3}-3 W T A_{1} \quad 2 W^{2} A_{3}-3 W T A_{2} \quad 2 W^{2} A_{2}-W_{1}-W T A_{3}$ Mean Mean Mean Mean}

Group (Std. dev.)

\section{Panel A: Aggregate data}

\begin{tabular}{|c|c|c|c|c|}
\hline $\begin{array}{l}\text { Pooled } \\
(\mathrm{n}=60)\end{array}$ & $\begin{array}{c}-1.12 * \\
(4.0)\end{array}$ & $\begin{array}{c}-1.96 \\
(8.1)\end{array}$ & $\begin{array}{l}-0.56 \\
(7.3)\end{array}$ & $\begin{array}{l}0.28 \\
(3.4)\end{array}$ \\
\hline $\begin{array}{l}\text { Inexperienced } \\
\text { consumers } \\
(n=34)\end{array}$ & $\begin{array}{c}-2.35^{*} \\
(4.9)\end{array}$ & $\begin{array}{c}-4.91 * \\
(9.2)\end{array}$ & $\begin{array}{c}-2.76^{*} \\
(7.1)\end{array}$ & $\begin{array}{l}-0.20 \\
(3.5)\end{array}$ \\
\hline $\begin{array}{l}\text { Experienced } \\
\text { consumers } \\
(n=26)\end{array}$ & $\begin{array}{c}0.50^{*} \\
(1.2)\end{array}$ & $\begin{array}{l}1.89^{*} \\
(4.1)\end{array}$ & $\begin{array}{l}2.32 \\
(6.6)\end{array}$ & $\begin{array}{c}0.92 \\
(3.2)\end{array}$ \\
\hline $\begin{array}{l}\text { Intense } \\
\text { consumers } \\
(\mathrm{n}=18)\end{array}$ & $\begin{array}{c}0.43 * \\
(0.8)\end{array}$ & $\begin{array}{l}1.34^{*} \\
(1.8)\end{array}$ & $\begin{array}{l}1.42^{*} \\
(3.2)\end{array}$ & $\begin{array}{l}0.50 \\
(1.7)\end{array}$ \\
\hline
\end{tabular}

\section{Panel B: Individual data-number of subjects satisfying each theory}

\begin{tabular}{lcccccccc}
$\begin{array}{l}\text { Pooled } \\
(\mathrm{n}=60)\end{array}$ & $\frac{\mathbf{N T}}{20}$ & $\frac{\mathbf{P T}}{23}$ & $\frac{\mathbf{N T}}{24}$ & $\frac{\mathbf{P T}}{27}$ & $\frac{\mathbf{N T}}{25}$ & $\frac{\mathbf{P T}}{25}$ & $\frac{\mathbf{N T}}{25}$ & $\frac{\mathbf{P T}}{20}$ \\
$\begin{array}{l}\text { Inexperienced } \\
\text { consumers } \\
(\mathrm{n}=34)\end{array}$ & 7 & 18 & 6 & 22 & 9 & 19 & 10 & 14 \\
$\begin{array}{l}\text { Experienced } \\
\text { consumers } \\
(\mathrm{n}=26)\end{array}$ & 13 & 5 & 18 & 5 & 16 & 6 & 15 & 6 \\
$\begin{array}{l}\text { Intense } \\
\text { consumers } \\
(\mathrm{n}=18)\end{array}$ & 9 & 3 & 13 & 3 & 13 & 3 & 11 & 4 \\
\hline
\end{tabular}

\footnotetext{
Notes: For definition of consumer types please see notes in Table 2. NT and PT denote neoclassical theory and prospect theory. Figures in Panel B on the number of subjects following each theory are determined by the signs of the four measures: $\mathrm{WTA}_{2}-2 \mathrm{WTA}_{1}$, $\mathrm{WTA}_{3}-3 \mathrm{WTA}_{1}, 2 \mathrm{WTA}_{3}-3 \mathrm{WTA}_{2}$, and $2 \mathrm{WTA}_{2}-\mathrm{WTA}_{1}$ $\mathrm{WTA}_{3}$. A positive value (implying convexity in the number of goods relinquished) is in favor of neoclassical theory whereas a negative value (implying concavity in the number of goods relinquished) favors prospect theory. A zero value indicates linearity and is not counted as following either theory; hence, the summation of the number of subjects following NT and PT for each convexity measure is not equal to the total number of subjects that participated. In panel A, a * indicates value is significantly different from zero at the $\mathrm{p}<.05$ level.
} 


\section{Variable WTA Function WTP Function}

\begin{tabular}{|c|c|c|}
\hline Constant & $-17.86(3.40) * *$ & $4.64(3.01)$ \\
\hline $\begin{array}{l}\text { Trading } \\
\text { intensity }\end{array}$ & $-0.74(0.13)^{* *}$ & $0.09(0.60)$ \\
\hline \multicolumn{2}{|c|}{$\begin{array}{l}\text { Yrs. of }-0.01 \\
\text { market experience }\end{array}$} & $-0.08(0.09)$ \\
\hline Income & $0.05(0.36)$ & $-0.38(0.41)$ \\
\hline Age & $-0.03(0.07)$ & $0.01(0.06)$ \\
\hline Gender & $2.10(2.20)$ & $3.79(1.91)^{* *}$ \\
\hline Education & $-0.02(0.03)$ & $0.17(0.33)$ \\
\hline $\mathrm{R}^{2}$ & 0.37 & --- \\
\hline$N$ & 55 & 47 \\
\hline \multicolumn{3}{|l|}{ Notes: } \\
\hline \multicolumn{3}{|c|}{$\begin{array}{l}\text { 1. Dependent variable is the individual's offer (or bid) in the three goods auction. In the WTP function, I } \\
\text { estimate a Tobit model and present marginal effects computed at the sample means. Gender }=1 \text { if male, } 0 \\
\text { otherwise. } \\
\text { 2. Standard errors are in parentheses beside coefficient estimates. } \\
\text { 3. Sample sizes may not match with sample sizes in Table } 1 \text { due to some respondents not including income } \\
\text { responses. Reported results omit these observations. If means are used to fill in the missing observations, } \\
\text { results are not quantitatively or qualitatively different from the results reported. } \\
\text { 4. **Denotes coefficient estimate is significant at the } p<.05 \text { level. }\end{array}$} \\
\hline
\end{tabular}




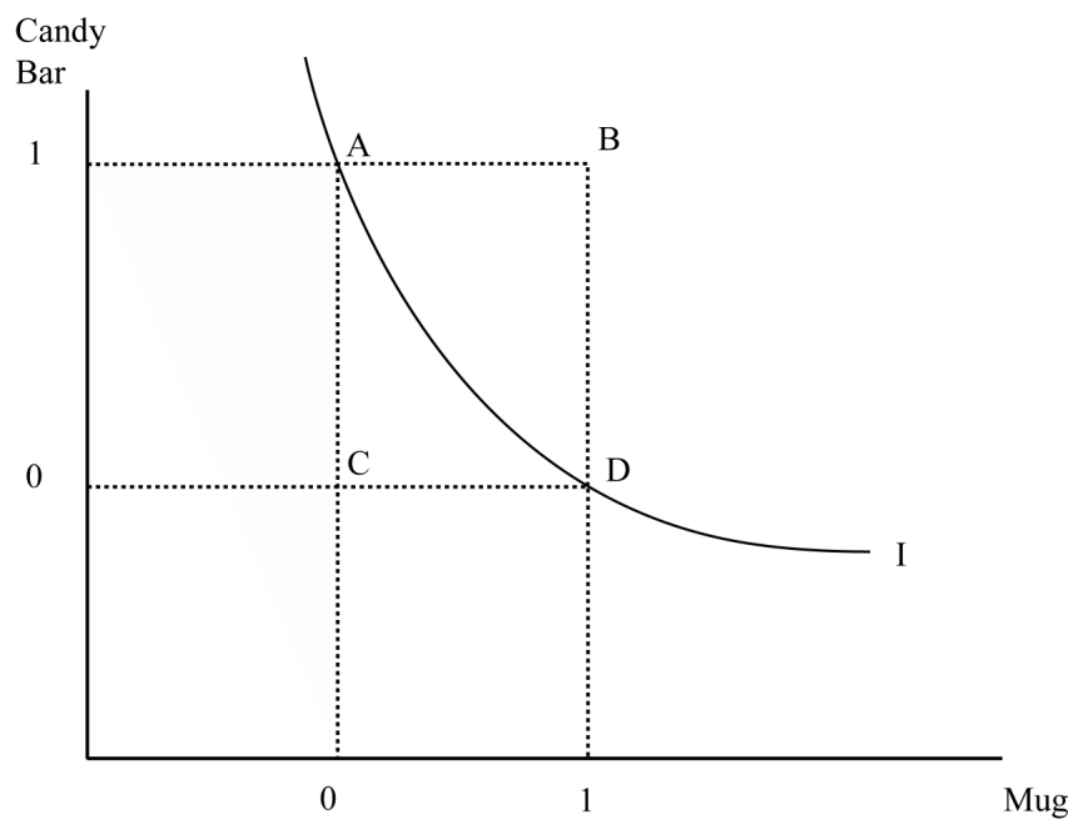

Figure 1. Experimental Design I

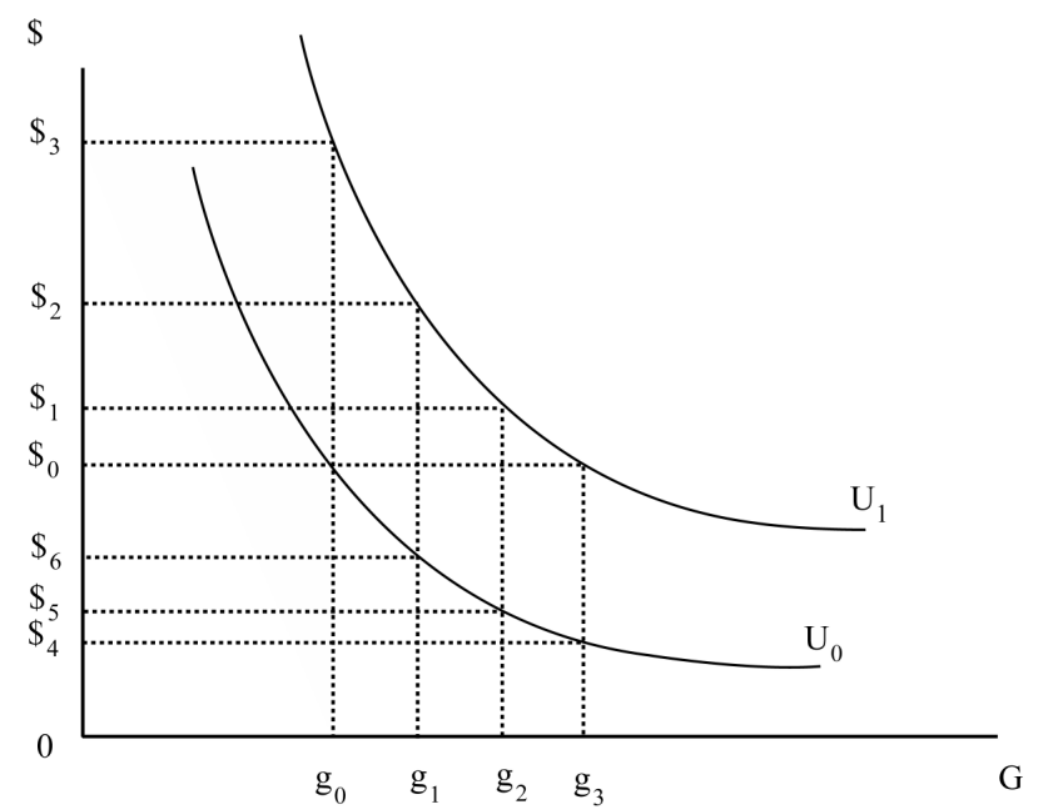

Figure 2. Experimental Design II 


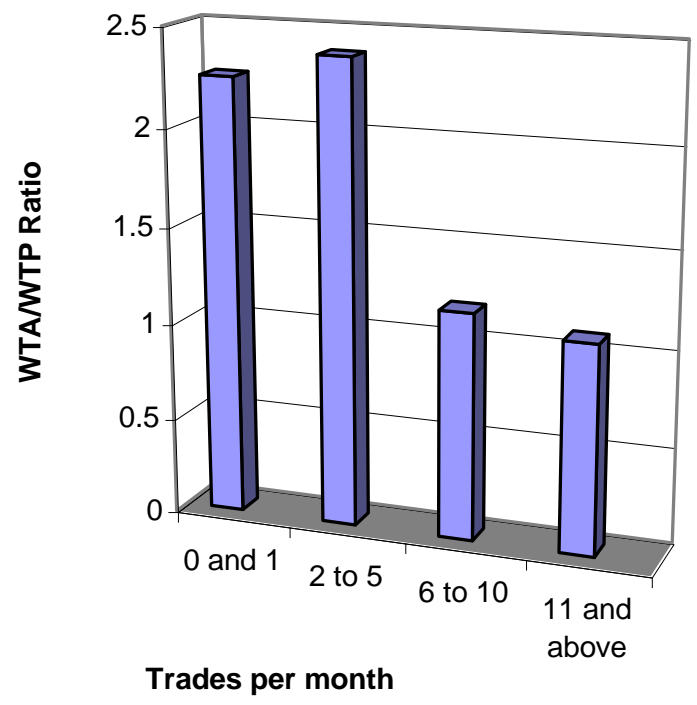

Figure 3. Summary of WTA/WTP Ratios 
These questions will be used for statistical purposes only. THIS INFORMATION WILL BE KEPT STRICTLY CONFIDENTIAL AND WILL BE DESTROYED UPON COMPLETION OF THE STUDY.

1. How long have you been active in the sportscards and memorabilia market? yrs

2. Approximately how many trades (cards or memorabilia) do you make in a typical month? . Note that trades could include pokemon cards, sportscards, other trading cards, and sports memorabilia.

Has your trading rate changed over time? Why?

3. Are you a sportscard or sports memorabilia professional dealer?

4. Gender: 1) Male 2) Female

5. Age — Date of Birth

6. What is the highest grade of education that you have completed. (Circle one)
1) Eighth grade
3) 2-Year College
5) 4-Year College
2) High School
4) Other Post-High School
6) Graduate School Education

7. What is your approximate yearly income from all sources, before taxes?
1) Less than $\$ 10,000$
5) $\$ 40,000$ to $\$ 49,999$
2) $\$ 10,000$ to $\$ 19,999$
6) $\$ 50,000$ to $\$ 74,999$
3) $\$ 20,000$ to $\$ 29,999$
7) $\$ 75,000$ to $\$ 99,999$
4) $\$ 30,000$ to $\$ 39,999$
8) $\$ 100,000$ or over 


\section{Appendix B. Subject Instructions for WTP Vickrey Second-Price Auction}

Welcome to Lister's Auctions. The money that I have just given you is yours to keepthanks for participating! You now have the opportunity to bid in an auction for the candy bars on the table.

\section{Auction Rules:}

A sealed bid second-price auction will be used to determine the winner of the auction. Thus, if your bid of $\$ \mathrm{X}$ is the highest bid and the next highest bid is $\$ \mathrm{X}-\mathrm{Z}$, you win the auction but only pay $\$ \mathrm{X}-\mathrm{Z}$. Under this bidding mechanism it is best for you to bid your true value because overbidding may cause you to pay too much and underbidding decreases your odds of winning the auction.

I will accept bids until Sunday at 5PM. On Monday morning I will order the bids from highest to lowest in order to determine the winner.

For example, if the top four bids are ranked highest to lowest as follows:

$$
\begin{aligned}
& \$ A \\
& \$ B \\
& \$ C \\
& \$ D
\end{aligned}
$$

The bidder who bid $\mathbf{\$ A}$ wins the auction and pays $\mathbf{\$ B}$.

Note that there are three candy bars on the table. I am going to have you place three bids. The first bid will be your bid for 1 of the candy bars - this is called auction 1 . Your second bid will be your bid for 2 of the candy bars - this will be auction 2 . Your third bid will be your bid for all $\underline{3}$ of the candy bars - this will be auction 3 .

But, it is important to note that only one of the three auctions will be for real. To decide which one is for real, on Sunday night at 5PM I will roll the six-sided on the table. If a 1 or 2 is rolled, the first auction will be for real; a roll of 3 or 4 and the second auction will be for real; finally, a roll of 5 or 6 and the third auction will be for real.

Note that in this setting it is optimal for you to bid your true value in each of the three auctions.

Given that the winner of the auction will pay a price equal to the amount of the second-highest bid, please place your bids below:

\section{1 candy bar $\$ \_2$ candy bars $\$$ _ 3 candy bars $\$$}

After the winner pays me cash or check, the good(s) will be awarded to the winner (we pay postage). Please sign the dotted line below to verify your bids. Also, please provide your name, telephone number and mailing address below:

Signature Printed Name

Address or email

Phone\# 